\title{
Patterns and risk factors of cognitive decline among community-dwelling Korean older adults: The Korean Longitudinal Study of Aging (2006-2016)
}

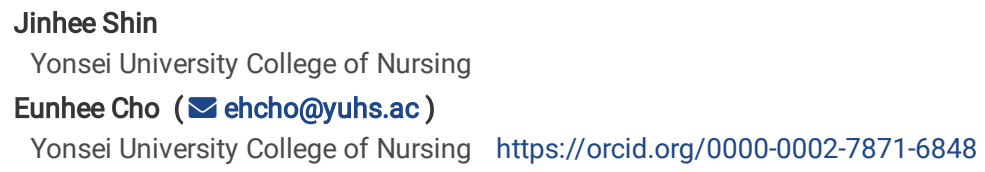

Research article

Keywords: Older adults, Cognitive function, Dementia, Korea

Posted Date: August 14th, 2020

DOI: https://doi.org/10.21203/rs.3.rs-42691/v1

License: () (7) This work is licensed under a Creative Commons Attribution 4.0 International License. Read Full License 


\section{Abstract \\ Background}

Dementia prevalence is increasing worldwide, and thus, the global impact of cognitive impairment and dementia has become a priority public health issue. This study aimed to assess the patterns of and risk factors for cognitive decline over time in community-dwelling Korean adults aged $\geq 65$ years.

\section{Methods}

Older adults with normal cognitive function at baseline in 2006 were evaluated, and changes in their cognitive function were followed over time. The data were obtained from the 2006-2016 Korean Longitudinal Study of Aging. Cognitive function in 2016 was classified based on the Korean-Mini-Mental State Examination score as normal, mild dementia, and moderate and severe dementia. The t-test, ANOVA, and linear mixed models were used to analyse the patterns and risk factors $f$ cognitive decline over time.

\section{Results}

Of the 1,262 participants examined, 752 maintained normal cognitive function, 267 older adults showed a change from normal cognitive function to mild dementia, and 243 older adults showed a decline from normal cognitive function to moderate and severe dementia between 2006 and 2016 . There were significant differences in cognitive function over time among the three groups, and these were influenced by age, gender, education level, religion, activities of daily living, instrumental activities of daily living, regular exercise, number of meetings with friends, and depression. The differences have gradually increased over 10 years.

\section{Conclusions}

This study identified the patterns of cognitive decline over time and important factors related to cognitive decline. Individualised interventions such as improving physical function through regular exercise, increasing social activity, and managing depression by early detection and treatment may contribute to maintain cognitive function.

\section{Background}

The ageing of the population has become a global phenomenon (1), including in South Korea with its rapidly aging society and where the population aged $\geq$ 65 years is projected to account for $41 \%$ of the total population by 2060 (2). Accordingly, the global impact of age-related cognitive impairment and dementia has become a priority public health issue. The prevalence of dementia is increasing worldwide. In 2015, 47.47 million individuals had dementia, and this is projected to increase to 75.63 million by 2030 and to 135.46 million by 2050 (3). Dementia is a health condition characterised by a combination of cognitive decline and physical and psychological symptoms that continually aggravates until death. Therefore, people with dementia need long-term care, which is challenging not only for the patients but also for their families, communities, and the country in general (4).

The global social cost of dementia in 2015 was 818 million, an increase of $35 \%$ since 2010, with most of the cost spent on care other than medical treatment (5). In South Korea, the economic cost of dementia was approximately 10 billion dollars in 2016 , and it is estimated that it will increase by two times in 10 years and reach approximately 100 billion dollars in 2050 (6). Given these trends, it is essential to determine the cause of cognitive impairment and identify methods to delay its development and reduce the associated social costs. As such, there have been many studies on the factors affecting cognitive decline ( 7 , $8,9,10)$. Demographic variables such as age $(11,12)$, lower education level $(13,14)$, being unmarried $(15)$, female gender $(16)$, having no religion $(17)$, physical function decline (18), depression (19), and decrease in social networks (15) were identified as high risk factors of cognitive decline. Concurrently, early management of cognitive decline is expected to prevent or delay the progress of dementia. In the United States, delaying the onset of dementia by 1 to 5 years has been reported to reduce its incidence by 770,000 to 4.04 million (20). Notwithstanding these estimates, few studies have examined the pattern of cognitive impairment and its influencing factors. The current study aimed to explore the patterns of cognitive decline in community-dwelling older adults and its associated factors, using a nationally representative survey of older adults followed for 10 years.

\section{Methods}

\section{Data source and ethical statement}

Data were obtained from the Korean Longitudinal Study of Ageing (KLoSA) conducted by the Korea Labor Institute. The KLoSA research panel survey, which has been conducted every two years since 2006, is a longitudinal panel survey of a nationally representative multistage and stratified probability sample of community-dwelling adults aged $\geq 45$ years. It uses computer-assisted personal interviews and includes various demographic, economic, and health-related topics (21). The KLoSA database has been opened to the public since 2016, and anonymised data can be downloaded from the Korea Labor Institute website. The KLoSA study was approved by the National Statistical Office (Approval number: 33602), and used a computer-assisted personal interview (CAPI), in which participants voluntarily clicked the start button to indicate consent to participation. Prior to the survey, researchers explained the purpose, methods, and other procedures of the survey to participants in the face-to-face meeting. The participants then clicked the start survey button using CAPI, if they agreed to participate. This study protocol was approved by the Yonsei University Health System Research Ethics Committee (Y-2019-0043). 


\section{Participants}

This study analysed data from KLosA participants aged $\geq 65$ years with normal cognitive function in 2006 who completed the survey for 10 years until the sixth investigation in 2016. Cognitive function was measured using the Korean-Mini-Mental State Examination (K-MMSE) score (22) in the KLoSA survey. The participants were classified into one of three groups according to their K-MMSE score in the 2016 survey: normal cognition (K-MMSE score $\geq 24$ ), mild dementia (K-MMSE score 20-23), and moderate and severe dementia (K-MMSE score $\leq 19$ ). This was a prospective cohort study in which participants without cognitive impairment were excluded at the initial stage. All participants included had the ability to understand the information from the researchers and to click the start button voluntarily; this was considered as an informed consent to participate in the survey (23). When a participant did not have the decisional capacity to participate in the survey owing to cognitive decline, a legal representative participated in the survey on the participant's behalf.

\section{Variables}

\section{Cognitive function}

Cognitive function was measured using the K-MMSE. Briefly, the K-MMSE consists of six domains of time and place orientation, registration, attention and calculation, recall, language, and visual construction. The maximum total K-MMSE score is 30 points, and mild dementia and moderate and severe dementia are defined as scores of $\leq 23$ and $\leq 19$, respectively (22).

\section{Demographic characteristics}

The demographic factors included age, gender, education level, marital status, religion, and total household income in 2006. Age was regarded as a continuous variable, and educational level was classified into illiteracy, elementary school, middle school, high school, and college or higher. Income was defined as the total household income in the previous year and was considered a continuous variable. Having a spouse and religion was measured with two responses "Yes" and "No".

\section{Health status and behaviours}

Health status and behaviours were assessed using the Korean activities of daily living (K-ADL), Korean instrumental activities of daily living (K-IADL), regular exercise, and depression scales. The K-ADL scale comprises seven items: dressing, washing face and hands, bathing, eating, transfer, toileting, and continence (24). The K-IADL scale comprises 10 items: shopping, mode of transportation, ability to handle finances, housekeeping, preparing food, ability to use a telephone, responsibility for own medication, recent memory, hobbies, watching television, and fixing the house (25). A higher score in both ADL and IADL scales indicates higher dependency. ADL and IADL were analysed as continuous variables. Regular exercise was measured with two responses "Yes" and "No". Depression was measured using the 10-item short-form of the Center for Epidemiological Studies Depression (CES-D10) scale modified Korean version (26), which is divided into two parts: positive and negative experiences. A CES-D10 scale score higher than 4 points indicates depression (26).

\section{Social interactions}

Social interaction was measured according to the number of meetings with friends (one question) and the number of participations in regular meetings (six question) to measure the social network. Answers related to the number of meetings with friends were measured on a 9-point scale ranging from 0 (not in contact) to 9 (almost every day). For the analysis, the number of meeting with friends was classified into fewer than six times a year, fewer than four times a month, and almost every day. Regular meetings were categorised into six activities: religious meetings, social meetings, leisure/culture/sports meetings, alumni/birthplace meetings, volunteer service, and political party/civic society organisations/interest groups. For analysis, the participations in regular meetings was based on the number of activities (range, 0 to 6 ).

\section{Statistical analysis}

Descriptive statistics, such as frequency (\%) and averages, standard deviation (SD), and median (interquartile range), of demographic characteristics, health status and health behaviour, and social interaction were used in the first step of the analysis. The changes and the differences in the K-MMSE score between the three groups were analysed using mean and SD, via analysis of variance. A linear mixed model was used to analyse the patterns and risk factors of cognitive decline; these were identified by confirming significance in the three groups over time from 2006 and 2016 . All statistical analyses were conducted using the PASW SPSS WIN 24.0 programme (SPSS Inc., Chicago, IL), and $p \leq 0.05$ was considered statistically significant.

\section{Results}

\section{Participant characteristics}

A total of 1,262 older adults were included in the study. Of these, 243 declined from normal cognitive function to moderate and severe dementia, 267 changed from normal cognitive function to mild dementia, and 752 maintained normal cognitive function between 2006 and 2016 . Table 1 shows the differences in demographic characteristics, health status and health behaviour, and social interaction among the three groups in 2006. In the overall population, the average age was $69.89(\mathrm{SD}=4.25$ ) years; $52 \%$ were female; $40.5 \%$ were elementary school graduates; and $74.4 \%$ had a spouse. Further, $32.8 \%$ had depression. There were significant differences in age, gender, education level, spouse, income, depression, regular exercise, and number of participations in regular meetings among the three groups. 
Table 1

Characteristics of the participants in 2006 by cognitive function group $(n=1262)$

\begin{tabular}{|c|c|c|c|c|c|}
\hline Variables & $\begin{array}{l}\text { Total } \\
(n=1262)\end{array}$ & $\begin{array}{l}\text { Moderate and severe } \\
\text { dementia } \\
(n=243)\end{array}$ & $\begin{array}{l}\text { Mild dementia }(n= \\
\text { 267) }\end{array}$ & $\begin{array}{l}\text { Normal }(n= \\
752)\end{array}$ & $p$-value \\
\hline Age, mean & $\begin{array}{l}69.89 \pm \\
4.25\end{array}$ & $71.64 \pm 4.83$ & $70.19+4.32$ & $69.22 \pm 3.83$ & $<.001$ \\
\hline \multicolumn{6}{|l|}{ Gender, n (\%) } \\
\hline Male & $606(48.0)$ & $95(39.1)$ & $122(45.7)$ & $439(58.4)$ & $<.001$ \\
\hline Female & $656(52.0)$ & $148(60.9)$ & $145(54.3)$ & $313(41.6)$ & \\
\hline \multicolumn{6}{|l|}{ Education level, n (\%) } \\
\hline Illiteracy & $193(15.3)$ & $56(23.0)$ & $62(23.2)$ & $75(10.0)$ & $<.001$ \\
\hline Elementary school & $511(40.5)$ & $120(49.4)$ & $112(41.9)$ & $279(37.1)$ & \\
\hline Middle school & $193(15.3)$ & $23(9.5)$ & $44(16.5)$ & $126(16.8)$ & \\
\hline High school & $236(18.7)$ & $30(12.3)$ & $36(13.5)$ & $170(22.6)$ & \\
\hline College or higher & $129(10.2)$ & $14(5.8)$ & $13(4.9)$ & $102(13.6)$ & \\
\hline \multicolumn{6}{|l|}{ Existence of spouse: n (\%) } \\
\hline Yes & $939(74.4)$ & $159(65.4)$ & $194(72.7)$ & $586(77.9)$ & $<.001$ \\
\hline No & $323(25.6)$ & $84(34.6)$ & $73(27.3)$ & $166(22.1)$ & \\
\hline \multicolumn{6}{|l|}{ Have a religion, $n(\%)$} \\
\hline Yes & $546(43.3)$ & $105(43.2)$ & $105(43.2)$ & $327(43.5)$ & .975 \\
\hline No & $716(56.7)$ & $138(56.8)$ & $153(57.3)$ & $425(56.5)$ & \\
\hline Total household income & $1132.18 \pm$ & $1010.18 \pm$ & $859.36 \pm$ & $1132.18 \pm$ & $<.010$ \\
\hline$(10,000$ won $)$, mean & 2016.14 & 1651.23 & 1157.42 & 2016.14 & \\
\hline \multicolumn{6}{|l|}{ Depression (CES-D10), n (\%) } \\
\hline Yes & $413(32.8)$ & $100(41.3)$ & $100(37.6)$ & $213(28.4)$ & $<.001$ \\
\hline No & $846(67.2)$ & $142(58.7)$ & $166(62.4)$ & $538(71.6)$ & \\
\hline ADL score, mean & $0.04 \pm 0.37$ & $0.03 \pm 0.29$ & $0.06+0.61$ & $0.04 \pm 0.37$ & .533 \\
\hline IADL sore, mean & $0.25+0.88$ & $0.36 \pm 1.11$ & $0.22 \pm 0.90$ & $0.23 \pm .78$ & .089 \\
\hline Regular exercise, n (\%) & & & & & .004 \\
\hline Yes & $532(42.2)$ & $85(35.0)$ & $102(38.2)$ & $345(45.9)$ & \\
\hline No & $730(57.8)$ & $158(65.0)$ & $165(61.8)$ & $407(54.1)$ & \\
\hline \multicolumn{6}{|l|}{ Number of meetings with friends, $\mathrm{n}(\%)$} \\
\hline $1-6$ times annually & $208(16.5)$ & $41(16.9)$ & $40(15.0)$ & $127(16.9)$ & .289 \\
\hline $1-4$ times a month & $581(46.0)$ & $108(44.4)$ & $113(42.3)$ & $360(47.9)$ & \\
\hline Almost daily & $473(37.5)$ & $94(38.7)$ & $114(42.7)$ & $265(35.2)$ & \\
\hline $\begin{array}{l}\text { Number of participations in regular meetings, } \\
\text { mean }\end{array}$ & $1.32 \pm 0.65$ & $1.28 \pm 0.64$ & $1.23 \pm 0.50$ & $1.37 \pm 0.69$ & .004 \\
\hline
\end{tabular}

The average age was $71.64,70.19$, and 69.22 years for those with moderate and severe dementia, mild dementia, and normal cognition, respectively. The proportion of females was $19.3 \%$ greater in the moderate and severe dementia group and $6.6 \%$ greater in the mild dementia group than that in the normal group. The proportion of elementary school graduates were in the moderate and severe dementia group, $12.3 \%$ higher, and in the mild dementia group, $4.8 \%$ were more than the normal group. For those with a spouse, $65.4 \%$ were in the moderate and severe dementia group, $72.7 \%$ in the mild dementia group, and $77.9 \%$ in the normal group. In the normal group, the average income was 1132.18 (SD $=2016.14)(10,000$ South Korean won), and the number of regular meeting was 1.37 (SD = 0.69), the highest among the three groups. Regular exercise was performed by $65 \%$ of patients in the moderate and severe dementia group, $61.8 \%$ in the mild dementia, and $54.1 \%$ in the normal group.

Changes in cognitive function 
Cognitive function (K-MMSE scores) was compared among the moderate and severe dementia, mild dementia, and normal groups (Table 2). Although the KMMSE scores were significantly different among the three groups $(p<.001)$, all three groups showed normal cognitive functions in 2006: the moderate and severe dementia group, 26.50 (SD = 1.91); mild dementia group, 26.71 ( $S D=1.93$ ); normal group, 27.60 (SD = 1.89). The K-MMSE score in 2016 significantly differed between the three groups $(F=2437.30, p<.001)$ (Table 2): the moderate and severe dementia group, 14.58 (SD = 4.46); mild dementia group, 21.61 $(S D=1.09)$; and normal group, 26.37 (SD = 2.00). During the 10-year period (2006-2016), the K-MMSE score decreased by 11.91 points in the moderate and severe dementia group, 5.1 points in the mild dementia group, and 0.23 points in the normal group. The K-MMSE score between 2006 and 2016 was significantly different among the three groups $(p<.001$, Fig. 1).

Table 2

Changes and differences in the Korean-Mini-Mental State Examination score according to group and year $(n=1262)$

\begin{tabular}{|lllll|}
\hline Year & Moderate and severe dementia $(n=243)$ & Mild dementia $(n=267)$ & Normal $(n=752)$ & Difference across groups \\
\cline { 2 - 5 } & Mean \pm SD & Mean \pm SD & Mean \pm SD & $F(p)$ \\
\hline 2006 & $26.50 \pm 1.91$ & $26.71 \pm 1.93$ & $27.60 \pm 1.89$ & $42.24(<.001)$ \\
\hline 2008 & $22.85 \pm 4.48$ & $24.68 \pm 3.85$ & $26.89 \pm 2.92$ & $130.44(<.001)$ \\
\hline 2010 & $22.36 \pm 5.08$ & $24.35 \pm 3.87$ & $26.52 \pm 3.33$ & $109.31(<.001)$ \\
\hline 2012 & $20.95 \pm 5.44$ & $24.14 \pm 4.01$ & $26.96 \pm 2.95$ & $234.93(<.001)$ \\
\hline 2014 & $18.18 \pm 5.97$ & $23.00 \pm 4.13$ & $26.64 \pm 3.15$ & $395.87(<.001)$ \\
\hline 2016 & $14.58 \pm 4.46$ & $21.61 \pm 1.09$ & $27.37 \pm 2.00$ & $2437.30(<.001)$ \\
\hline
\end{tabular}

Table 3 presents the differences in the average K-MMSE score among the three groups at each time point. There were significant differences for time and group. In the moderate and severe dementia group, the average difference in K-MMSE scores was statistically significant, except for 2008-2010, and decreased the most in 2006-2008 ( $\mathrm{t}=-12.05, p<.001)$. The average difference in the K-MMSE scores was also statistically significant in the mild dementia group, except for 2008-2010 and 2010-2012 and decreased the most in 2006-2008 $(\mathrm{t}=-6.48, p<.001)$. In the normal group, the average differences in the KMMSE scores were all statistically significant.

Table 3

Comparison and differences in the Korean-Mini-Mental State Examination score according to group and years $(n=1262)$

\begin{tabular}{|c|c|c|c|c|c|c|c|c|c|c|}
\hline \multirow[t]{2}{*}{ Group } & $\begin{array}{l}2006- \\
2008\end{array}$ & \multirow[t]{2}{*}{$t(p)$} & \multirow{2}{*}{$\begin{array}{l}2008- \\
2010 \\
\text { Mean } \\
\pm \text { SD }\end{array}$} & \multirow[t]{2}{*}{$t(p)$} & \multirow{2}{*}{$\begin{array}{l}2010- \\
2012 \\
\text { Mean } \\
\pm \text { SD }\end{array}$} & \multirow[t]{2}{*}{$t(p)$} & \multirow{2}{*}{$\begin{array}{l}2012- \\
2014 \\
\text { Mean } \\
\pm \text { SD }\end{array}$} & \multirow[t]{2}{*}{$t(p)$} & $\begin{array}{l}2014- \\
2016\end{array}$ & \multirow[t]{2}{*}{$\mathrm{t}(p)$} \\
\hline & $\begin{array}{l}\text { Mean } \pm \\
\text { SD }\end{array}$ & & & & & & & & $\begin{array}{l}\text { Mean } \\
\pm S D\end{array}$ & \\
\hline $\begin{array}{l}\text { Moderate and severe } \\
\text { dementia }(n=243)\end{array}$ & $\begin{array}{l}-3.65 \pm \\
4.60\end{array}$ & $-12.05(<.001)$ & $\begin{array}{l}-0.49 \pm \\
5.18\end{array}$ & $-1.52(.131)$ & $\begin{array}{l}-1.41 \pm \\
5.15\end{array}$ & $-3.91(<.001)$ & $\begin{array}{l}-2.77 \\
\pm 6.88\end{array}$ & $-5.80(<.001)$ & $\begin{array}{l}-3.60 \\
\pm 6.31\end{array}$ & $-8.53(<.001)$ \\
\hline $\begin{array}{l}\text { Mild dementia }(n= \\
\text { 267) }\end{array}$ & $\begin{array}{l}-2.03 \pm \\
3.98\end{array}$ & $-8.07(<.001)$ & $\begin{array}{l}-0.33 \pm \\
4.15\end{array}$ & $-1.09(.275)$ & $\begin{array}{l}-0.21 \pm \\
3.59\end{array}$ & $-.55(.581)$ & $\begin{array}{l}-1.14 \\
\pm 4.82\end{array}$ & $-3.76(<.001)$ & $\begin{array}{l}-1.39 \\
\pm 4.06\end{array}$ & $-5.47(<.001)$ \\
\hline Normal $(n=752)$ & $\begin{array}{l}-0.71 \pm \\
2.93\end{array}$ & $-6.48(<.001)$ & $\begin{array}{l}-0.37 \pm \\
3.50\end{array}$ & $-2.65(.008)$ & $\begin{array}{l}0.44 \pm \\
3.44\end{array}$ & $3.23(.001)$ & $\begin{array}{l}-0.32 \\
\pm 3.16\end{array}$ & $-2.89(.004)$ & $\begin{array}{l}0.73 \pm \\
3.05\end{array}$ & $6.54(<.001)$ \\
\hline
\end{tabular}

SD, standard deviation

\section{Risk factors of cognitive functional decline}

Table 4 presents the results of linear mixed models used to confirm the effects of risk factors on K-MMSE score. The variance inflation factor values for the multicollinearity confirmed the final model analysis was 1.03 to 1.53 , indicating that there was no multicollinearity. The K-MMSE score over time was significantly higher for the moderate and severe dementia group $(\beta=-0.503, p=.034)$ and mild dementia group $(\beta=-0.444, p=.050)$ than the normal group. With respect to the changes in the K-MMSE score over time, the K-MMSE score in $2008(\beta=-0.158, p<.001), 2010(\beta=-0.922, p<.001), 2012(\beta=-0.951, p<.001)$, $2014(\beta=-1.214, p<.001)$, and $2016(\beta=-0.865, p<.001)$ was significantly lower than that in 2006 , confirming that it was influenced by time. In addition, there were significant differences in the patterns of change in the K-MMSE score among the three groups. The K-MMSE scores in the moderate and severe dementia group in $2008(\beta=-2.922, p<.001), 2010(\beta=-2.896, p<.001), 2012(\beta=-4.536, p<.001), 2014(\beta=-6.637, p<.001)$, and 2016 ( $\beta=-10.422, p<.001)$ and in the mild dementia group in $2008(\beta=-1.292, p<.001), 2010(\beta=-1.225, p<.001), 2012(\beta=-1.826, p<.001), 2014(\beta=-2.699, p<.001)$, and $2016(\beta=-4.637, p$ $<.001$ ) were significantly lower than those in the normal group in 2006 , confirming the impact of time and group. 


\begin{tabular}{|c|c|c|}
\hline \multicolumn{3}{|l|}{ Variables } \\
\hline & B & p-value \\
\hline Age $(y)$ & -0.044 & .001 \\
\hline Male (ref: female) & 0.591 & $<.001$ \\
\hline \multicolumn{3}{|l|}{ Education level (ref: College or higher) } \\
\hline Illiteracy & -1.954 & $<.001$ \\
\hline Elementary school graduate & -0.967 & $<.001$ \\
\hline Middle school graduate & -0.981 & .002 \\
\hline High school graduate & -0.582 & .005 \\
\hline Religion (ref: No) & 0.368 & $<.001$ \\
\hline Total household income (10,000 won) & 3.326 & .117 \\
\hline Regular exercise (ref: No) & 0.326 & $<.001$ \\
\hline No Depression (CES-D10) (ref: Yes) & 0.486 & $<.001$ \\
\hline Existence of spouse (ref: Yes) & -0.182 & .113 \\
\hline ADL score & -0.057 & $<.001$ \\
\hline IADL score & -0.239 & $<.001$ \\
\hline \multicolumn{3}{|l|}{ Number of meetings with friends (ref: Almost daily) } \\
\hline Less than 6 times a year & -0.550 & $<.001$ \\
\hline 1-4 times a month & 0.109 & 0.205 \\
\hline Number of participations in regular meetings & 0.009 & .899 \\
\hline Group 1: moderate and severe dementia (ref: Normal) & -0.503 & .034 \\
\hline Group 2: Mild dementia (ref: Normal) & -0.444 & .050 \\
\hline Time (y): 2008 (ref :2006) & -0.158 & $<.001$ \\
\hline Time (y): 2010 (ref :2006) & -0.922 & $<.001$ \\
\hline Time (y): 2012 (ref :2006) & -0.951 & $<.001$ \\
\hline Time (y): 2014 (ref :2006) & -1.214 & $<.001$ \\
\hline Time (y): 2016 (ref :2006) & -0.865 & $<.001$ \\
\hline Group 1 (Moderate and severe dementia)^time 2008 (ref: Normal *time 2006) & -2.922 & $<.001$ \\
\hline Group 1 (Moderate and severe dementia)*time 2010 (ref: Normal *time 2006) & -2.896 & $<.001$ \\
\hline Group 1 (Moderate and severe dementia)*time 2012 (ref: Normal *time 2006) & -4.536 & $<.001$ \\
\hline Group 1 (Moderate and severe dementia)*time 2014 (ref :Normal *time 2006) & -6.637 & $<.001$ \\
\hline Group 1 (Moderate and severe dementia)*time 2016 (ref: Normal *time 2006) & -10.422 & $<.001$ \\
\hline Group 2 (Mild dementia)*time 2008 (ref: Normal *time 2006) & -1.292 & $<.001$ \\
\hline Group 2 (Mild dementia)*time 2010 (ref: Normal *time 2006) & -1.225 & $<.001$ \\
\hline Group 2 (Mild dementia)*time 2012 (ref: Normal *time 2006) & -1.826 & $<.001$ \\
\hline Group 2 (Mild dementia)*time 2014 (ref: Normal *time 2006) & -2.699 & $<.001$ \\
\hline Group 2 (Mild dementia)*time 2016 (ref: Normal *time 2006) & -4.637 & $<.001$ \\
\hline
\end{tabular}

The risk factors for cognitive decline in the three groups were age, gender, education level, religion, regular exercise, depression score, K-ADL, K-IADL, and number of meetings with friends. The K-MMSE score decreased as the age increased $(\beta=-0.044, p=.001)$. In education level, the K-MMSE score was significantly lower in the illiteracy $(\beta=-1.954, p<.001)$, elementary school graduate $(\beta=-0.967, p<.001)$, middle school graduate $(\beta=-0.981, p=.002)$, and high school graduate $(\beta=-0.582, p=.005)$ groups than that in the college or higher group. The K-MMSE score was also lower when the participants had a religion group compared with when they had no religion $(\beta=0.368, p<.001)$. Furthermore, as the K-ADL score $(\beta=-0.057, p<.001)$ and K-IADL score $(\beta=-0.239, p$ 
$<.001)$ increased, the K-MMSE score was significantly lower. For the number of meetings with friends, the K-MMSE score was significantly lower for those who met with their friends less than 6 times a year than in those who met with them almost daily $(\beta=-0.050, p<.001)$. Male $(\beta=0.591, p<.001)$, regular exercise $(\beta=0.326, p<.001)$, and no depression $(\beta=0.486, p<.001)$ were significantly associated with a higher K-MMSE score.

\section{Discussion}

Dementia is an important global health issue owing to the increasing elderly population. Given that cognitive decline is irreversible, preventive strategies to reduce the risk and delay the onset of dementia through early management of risk factors are important. Cognitive decline is distressing not only to the patient but also to their family and the country as a whole owing to the profound health and economic burden associated with it. Therefore, the importance of prevention and early detection of dementia has been emphasised, and attention to mild dementia as well as moderate and severe dementia is increasing.

In this study, 1,262 community-dwelling older adults were categorised according to their cognitive function as having moderate and severe dementia, mild dementia, or normal cognitive function and followed using changes in the K-MMSE score for 10 years. Of these, 243 older adults progressed to moderate and severe dementia, 267 older adults developed mild dementia, and 752 older adults maintained normal cognitive function. The K-MMSE score significantly differed over time among the moderate and severe dementia, the mild dementia, and the normal cognition groups. In the moderate and severe dementia group, the K-MMSE score was rapidly decreased after 6 years, while the mild dementia group showed a steady decrease in MMSE score over time. These results suggest that the rate of cognitive decline over time may be different in adults with normal cognitive function, and thus it is necessary to prevent the deterioration of cognitive function by conducting regular screening and managing risk factors.

The results of the current study are consistent with those of many previous studies that had identified factors of cognitive function decline. Cognitive decline was associated with age $(16,27,28)$, being female $(29)$, and level of education $(30,31)$. Given that the incidence of dementia increases with age, early management of the risk factors for dementia should be reinforced for early detection and prevention in old adults (32). In a systematic literature review study published from 1985 to 2010, 51 of 88 studies (58\%) reported significant negative effects of lower education on the risk for dementia (33). Furthermore, religion appears to have a preventive role in cognitive decline by providing mental stability and peace associated with participation in religious activities (34).

Health status and health behavioural factors, physical function ( $A D L, I-A D L)$, regular exercise, and depression were significantly different according to cognitive function. Several studies have reported that physical function is related to cognitive decline (35, 36); subjects with mild cognitive and IADL impairment are more likely to develop dementia than subjects with mild cognitive impairment but unrestricted IADL (36). Older adults with good physical function have high cognitive function (37).

The 6-month walking programme for nursing home residents with Alzheimer's disease has shown to improve ADL scores and stabilise the progressive cognitive dysfunctions and improvement (38). Physical exercise enhances and maintains the general health, quality of life, and physical fitness benefits of the older population. Regular exercise has recently been studied as a predictor of various physical health conditions, and interest in the relationship between physical health and cognitive function has been recently increasing. Studies have shown that regular exercise in older adults may delay the progression of dementia (39). Older adult females who are physically active have been reported to have low risk of cognitive decline (18). Walking lowers the risk of dementia, and thus older adults who exercise regularly are expected to have lower risk of cognitive decline (40). Exercise improves cognitive function and survival by stimulating nerve growth and nerve function and facilitating adequate blood, oxygen, and nutrient supply to the brain (41, 42). There is a need to better characterise walking behaviours and patterns related to cognitive age, including metabolism equivalents, that can be easily adopted by older adults individuals. Health care providers should also promote an active lifestyle for older adults.

Depression is known as the most common mental health disease in old age and strongly affects cognitive function. Consistent with other studies (16, 19,35 , 43), we also found that depression is associated with cognitive function decline, indicating that prevention and early detection and treatment of depression in older adults can prevent cognitive decline.

Further, social interaction, as evaluated according to the number of meetings with friends, was associated with a decrease in cognitive function. Particularly, older adults who met with friends less than six times a year developed decreased cognitive function compared with those who met with friends almost every day. These results suggested that continued participation in social activities was associated with decreased risk of cognitive function decline. This is consistent with findings on the associations between social participation and cognitive function $(44,45)$. A previous longitudinal study of community-dwelling adults and older adults suggested that maintaining many social activities may help prevent and delay cognitive function (44). A Taiwanese cohort study also showed that participating in more social activities reduces the risk of cognitive impairment (46). Therefore, it is necessary for community-dwelling older adults to actively implement programmes that enable the elderly in the community to continue social interaction.

This study had some limitations. First, while the pattern of K-MMSE was evaluated in a large cohort of 1262 older adults between 2006 and 2016 , we only included only community-dwelling older adults and not those living in nursing homes. Second, we may not have fully controlled all potential risks or confounding factors in this study; we could not include possible factors related to physical and mental health status except depression. Lastly, the results might be influenced by survival effects because we excluded censored participants such as those who died, admitted to a nursing home and those moved to a critical care unit due to severe dementia before the final survey in 2016 . However, despite these limitations, we believe that our study remains valuable in that it had a relatively longitudinal follow-up and used a representative elderly sample. In addition, by identifying risk factors that affect the K-MMSE score, the results can be utilised to improve care of the older adults in the future.

\section{Conclusion}


Ageing-related cognitive function decline is associated with high medical costs and family burden, thus making it an important issue today owing to the increasing ageing population. We found that demographic characteristics, health status, health behavioural factors, and social interaction influenced the risk for cognitive decline. Given that mild dementia can progress to moderate and severe dementia, timely and appropriate strategies according to the stage of cognitive impairment are needed to reduce personal, family, and social burdens. Improving physical function through regular exercise, increasing social activity, and managing depression via early detection and treatment according to the cognitive function status are recommended.

\section{Abbreviations}

K-MMSE, Korean-Mini-Mental State Examination

KLoSA, Korean Longitudinal Study of Ageing

CES-D10, Center for Epidemiological Studies Depression

SD, standard deviation

ADL, Activities of daily living

IADL, Instrumental activities of daily living

\section{Declarations}

\section{Ethics approval and consent to participate}

KLoSA maintains a national public database of the longitudinal panel survey. The KLoSA study was approved by the National Statistical Office (Approval number: 33602), and used a computer-assisted personal interview (CAPI) in which participants voluntarily clicked the start button to indicate consent to participate in the study. This was a prospective cohort study, in which participants without cognitive impairment were excluded at the initial stage. All participants had the ability to understand the information from the researchers and to click the start button voluntarily. This study was approved by the Yonsei University Health System Research Ethics Committee (Y-2019-0043).

\section{Consent for publication}

Not applicable

\section{Availability of data and materials}

The data used in this study are available at http://survey.keis.or.kr

\section{Competing interests}

The authors declare that they have no competing interests.

\section{Funding}

This research was supported by Basic Science Research Program through the National Research Foundation of Korea (NRF) funded by the Ministry of Education (No. 2020R1A6A1A03041989)

\section{Authors' contributions}

JS conceptualised and designed the study and performed the data analysis. JS and EC participated in the interpretation of analyses. All authors have read and approved the final manuscript.

\section{Acknowledgements}

Not applicable

\section{References}

1. World Health Organization. Dementia: a public health priority. 2012. https://www.who.int/mental_health/publications/dementia_report_2012/en/. Accessed 16 Aug 2019.

2. Prince $M$, Guerchet $M$, Prina M. The epidemiology and impact of dementia: current state and future trends. World Health Organization. 2015. https://www.who.int/mental_health/neurology/dementia/thematic_briefs_dementia/en/. Accessed 20 May 2019. 
3. Hong GS, Park KO, Oh EM. Assessment and suggestion on strategies to overcome dementia and its tasks: Nursing perspectives. Health Soc Welfare Rev. 2018;38:37-63.

4. Wimo A, Guerchet M, Ali GC, Wu YT, Prina AM, Winblad B, et al. The worldwide costs of dementia 2015 and comparisons with 2010. Alzheimers Dement. 2017;13:1-7.

5. Central Dementia Center. Central Dementia Center annual report 2016. https://www.nid.or.kr/notification/notice_view.aspx?board_seq=1299. Accessed 20 May 2019.

6. Seliger SL, Wendell CR, Waldstein SR, Ferrucci L, Zonderman AB. Renal function and long-term decline in cognitive function: The Baltimore Longitudinal Study of Aging. Am J Nephrol. 2015;41:305-12.

7. Wu MS, Lan TH, Chen CM, Chiu HC, Lan TY. Socio-demographic and health-related factors associated with cognitive impairment in the elderly in Taiwan.". BMC Public Health. 2011;11:22.

8. Sun Y, Lee HJ, Yang SC, Chen TF, Lin KN, Lin CC, et al. A nationwide survey of mild cognitive impairment and dementia, including very mild dementia, in Taiwan. PloS One. 2014;9:e100303.

9. Kim S, Kim Y, Park SM. Association between alcohol drinking behaviour and cognitive function: results from a nationwide longitudinal study of South Korea. BMJ Open. 2016;6:e010494.

10. Kim HK, Kim YS, Kim TY. Effects of age, education and gender on multiple cognitive measures of Korean older adults. Korean J Clin Psych. 2011;30:681701.

11. Jeon HS. An exploratory study on the predictors of cognitive improvement among older adults: Using Korean Longitudinal Study of Aging(KLoSA). Health Soc Welfare Rev. 2013;33:461-88.

12. Kim HK, Kim YS, Kim TY. Effects of age, education and gender on multiple cognitive measures of Korean older adults. Korean J Clin Psych. 2011;30:681701.

13. Anstey $\mathrm{K}$, Christensen $\mathrm{H}$. Education, activity, health, blood pressure and apolipoprotein $\mathrm{E}$ as predictors of cognitive change in old age: a review. Gerontology. 2000;46;163 - 77.

14. Fratiglioni L, Wang HX, Ericsson K, Maytan M, Winblad B. Influence of social network on occurrence of dementia: a community-based longitudinal study. Lancet. 2000;355:1315-9.

15. Lee HJ, Kang SK. Age and gender differences in cognitive functioning among elderly. Ment Health Soc Work. 2011;37:255-78.

16. Ha MS, Park RJ. A study of cognitive function and depression of the elderly in a institution. J Korean Soc Phys Med. 2008;3:285-92.

17. Middleton LE, Barnes DE, Lui LY, Yaffe K. Physical activity over the life course and its association with cognitive performance and impairment in old age. $J$ Am Geriatr Soc. 2010;58:1322-6.

18. Barnes DE1, Alexopoulos GS, Lopez OL, Williamson JD, Yaffe K. Depressive symptoms, vascular disease, and mild cognitive impairment: findings from the Cardiovascular Health Study. Arch Gen Psychiatry. 2006;63:273-9.

19. Brookmeyer R, Gray S, Kawas C. Projections of Alzheimer's disease in the United States and the public health impact of delaying disease onset. Am J Public Health. 1998;88:1337-42.

20. Boo KC, Chang JY. Korean longitudinal study of ageing: research design for international comparative studies. Surv Res. $2006 ; 7: 97-122$.

21. Kang YW, Na DL, Hahn SH. A validity study on the Korean Mini-Mental State Examination (K-MMSE) in dementia patients. J Korean Neurol Assoc. 1997;15:300.

22. Callegaro M, DiSogra C. Computing response metrics for online panels. Public Opinion Quarterly. 2008;72(5):1008-32.

23. Won CW, Rho YG, Kim SY, Cho BR, Lee YS. The validity and reliability of Korean Activities of Daily Living (K-ADL) scale. J Korean Geriat Soc. 2002;6:98106.

24. Kang SJ, Choi SH, Lee BH, Kwon JC, Na DL, Han SH. The reliability and validity of the Korean Instrumental Activities of Daily Living (K-IADL). J Korean Neurol Assoc. 2002;20;8.

25. Chon KK. Preliminary development of Korean version of CES-D. Korean J Clin Psychol. 1992;11:65-76.

26. Kim EJ. Factors influencing cognitive impairment of the elderly residents. J East-West Nursing Res. 2010;16:122-30.

27. Hwang YJ, Kim SH, Shin EY, Kim SH, Jeong WM. The comparison of level of cognitive function. Journal of Korean Society of Neurocognitive Rehabilitation. 2013;5:9-17.

28. Ha EH, Park KS. Factors influencing cognitive impairment in elders with dementia living at home. J Korean Acad Nurs. 2011;18:317-27.

29. Koster A, Penninx BW, Bosma H, Kempen GI, Newman AB, Rubin SM, et al. Socioeconomic differences in cognitive decline and the role of biomedical factors. Ann Epidemiol. 2005;15:564-71.

30. Wilson R, Hebert L, Scherr P, Barnes L, Mendes de Leon CM, Evans D. Educational attainment and cognitive decline in old age. Neurology. 2009;72:460-4.

31. Ministry of Health and Welfare. 2012 survey of dementia prevalence[Internet]. Seoul: Author; 2013. https://www.mohw.go.kr/react/al/sal0301vw.jsp? PAR_MENU_ID=04\&MENU_ID=0403\&CONT_SEQ=286138. Accessed 16 Aug 2019.

32. Sharp ES, Gatz M. Relationship between education and dementia: An updated systematic review. Alzheimer Dis Assoc Disord. 2011;25:289-304.

33. Corsentino E, Collins N, Sachs-Ericsson N, Blazer D. Religious attendance reduces cognitive decline among older women with high levels of depressive symptoms. J Gerontol A Biol Sci Med Sci. 2009;64:1283-9.

34. Chodosh J, Miller-Martinez D, Aneshensel CS, Wight RG, Karlamangla AS. Depressive symptoms, chronic diseases, and physical disabilities as predictors of cognitive functioning trajectories in older Americans. J Am Geriatr Soc. 2010;58:2350-7.

Page 9/14 
35. Luck T, Luppa M, Briel S, Matschinger $\mathrm{H}$, Konig HH, Bleich S, et al. Mild cognitive impairment: incidence and risk factors: results of the leipzig longitudinal study of the aged. J Am Geriatr Soc. 2010;58:1903-10.

36. Lee YM. Influence of behavioral and psychological symptoms on pain in nursing home residents with cognitive impairment. J Korean Soc Wellness. 2016;11:107-16.

37. Venturelli M, Scarsini R, Schena F. Six-month walking program changes cognitive and ADL performance in patients with Alzheimer. Am J Alzheimers Dis Other Demen. 2011;26:381-8.

38. Larson EB, Wang L, Bowen JD, McCormick WC, Teri L, Crane P, et al. Exercise is associated with reduced risk for incident dementia among persons 65 years of age and older. Ann Intern Med. 2006;144:73-81.

39. Abbott RD, White LR, Ross GW, Masaki KH, Curb JD, Petrovitch H. Walking and dementia in physically capable elderly men. JAMA. 2004;292:1447-53.

40. Santana-Sosa E, Barriopedro M, López-Mojares LM, Pérez M, Lucia A. Exercise training is beneficial for Alzheimer's patients. Int J Sports Med. 2008;29:845-50.

41. Hageman PA, Thomas VS. Gait performance in dementia: the effects of a 6-week resistance training program in an adult day-care setting. Int J Geriatr Psychiatry. 2002;17:329-34.

42. Kim BJ, Liu L, Cheung C, Ahn J. Effects of cognitive impairment and functional limitation on depressive symptoms among community-dwelling older Korean immigrants in the US. PloS One. 2018;13:e0193092.

43. Crooks VC, Lubben J, Petitti DB, Little D, Chiu V. Social network, cognitive function, and dementia incidence among elderly women. Am J Public Health. 2008;98:1221-7.

44. Choi Y, Park S, Cho KH, Chun SY, Park EC. A change in social activity affect cognitive function in middle-aged and older Koreans: analysis of a Korean longitudinal study on aging (2006-2012). Int J Geriatr Psychiatry. 2016;31:912-9.

45. Glei DA, Landau DA, Goldman N, Chuang Y-L, Rodríguez G, Weinstein M. Participating in social activities helps preserve cognitive function: an analysis of a longitudinal, population-based study of the elderly. Int J Epidemiol. 2005;34:864-71.

46. 46. Glei DA, Landau DA, Goldman N, Chuang Y-L, Rodríguez G, Weinstein M. Participating in social activities helps preserve cognitive function: an analysis of a longitudinal, population-based study of the elderly. Int J Epidemiol. 2005;34:864 - 71.

\section{Tables}

Table 1. Characteristics of the participants in 2006 by cognitive function group $(n=1262)$ 


\begin{tabular}{|c|c|c|c|c|c|}
\hline Variables & $\begin{array}{l}\text { Total } \\
(n=1262)\end{array}$ & $\begin{array}{l}\text { Moderate and severe } \\
\text { dementia } \\
(n=243)\end{array}$ & $\begin{array}{l}\text { Mild dementia } \\
(n=267)\end{array}$ & $\begin{array}{l}\text { Normal } \\
(n=752)\end{array}$ & $p$-value \\
\hline Age, mean & $69.89 \pm 4.25$ & $71.64 \pm 4.83$ & $70.19+4.32$ & $69.22 \pm 3.83$ & $<.001$ \\
\hline \multicolumn{6}{|l|}{ Gender, n (\%) } \\
\hline Male & $606(48.0)$ & $95(39.1)$ & $122(45.7)$ & $439(58.4)$ & $<.001$ \\
\hline Female & $656(52.0)$ & $148(60.9)$ & $145(54.3)$ & $313(41.6)$ & \\
\hline \multicolumn{6}{|l|}{ Education level, n (\%) } \\
\hline Illiteracy & $193(15.3)$ & $56(23.0)$ & $62(23.2)$ & $75(10.0)$ & $<.001$ \\
\hline Elementary school & $511(40.5)$ & $120(49.4)$ & $112(41.9)$ & $279(37.1)$ & \\
\hline Middle school & $193(15.3)$ & $23(9.5)$ & $44(16.5)$ & $126(16.8)$ & \\
\hline High school & $236(18.7)$ & $30(12.3)$ & $36(13.5)$ & $170(22.6)$ & \\
\hline College or higher & $129(10.2)$ & $14(5.8)$ & $13(4.9)$ & $102(13.6)$ & \\
\hline \multicolumn{6}{|l|}{ Existence of spouse: n (\%) } \\
\hline Yes & $939(74.4)$ & $159(65.4)$ & $194(72.7)$ & $586(77.9)$ & $<.001$ \\
\hline No & $323(25.6)$ & $84(34.6)$ & $73(27.3)$ & $166(22.1)$ & \\
\hline \multicolumn{6}{|l|}{ Have a religion, $n(\%)$} \\
\hline Yes & $546(43.3)$ & $105(43.2)$ & $105(43.2)$ & $327(43.5)$ & .975 \\
\hline No & $716(56.7)$ & $138(56.8)$ & $153(57.3)$ & $425(56.5)$ & \\
\hline Total household income & $1132.18 \pm$ & $1010.18 \pm$ & $859.36 \pm$ & $1132.18 \pm$ & $<.010$ \\
\hline$(10,000$ won), mean & 2016.14 & 1651.23 & 1157.42 & 2016.14 & \\
\hline \multicolumn{6}{|l|}{ Depression (CES-D10), n (\%) } \\
\hline Yes & $413(32.8)$ & $100(41.3)$ & $100(37.6)$ & $213(28.4)$ & $<.001$ \\
\hline No & $846(67.2)$ & $142(58.7)$ & $166(62.4)$ & $538(71.6)$ & \\
\hline ADL score, mean & $0.04 \pm 0.37$ & $0.03 \pm 0.29$ & $0.06+0.61$ & $0.04 \pm 0.37$ & .533 \\
\hline IADL sore, mean & $0.25+0.88$ & $0.36 \pm 1.11$ & $0.22 \pm 0.90$ & $0.23 \pm .78$ & .089 \\
\hline Regular exercise, n (\%) & & & & & .004 \\
\hline Yes & $532(42.2)$ & $85(35.0)$ & $102(38.2)$ & $345(45.9)$ & \\
\hline No & $730(57.8)$ & $158(65.0)$ & $165(61.8)$ & $407(54.1)$ & \\
\hline \multicolumn{6}{|l|}{ Number of meetings with friends, $n(\%)$} \\
\hline $1-6$ times annually & $208(16.5)$ & $41(16.9)$ & $40(15.0)$ & $127(16.9)$ & .289 \\
\hline $1-4$ times a month & $581(46.0)$ & $108(44.4)$ & $113(42.3)$ & $360(47.9)$ & \\
\hline Almost daily & $473(37.5)$ & $94(38.7)$ & $114(42.7)$ & $265(35.2)$ & \\
\hline $\begin{array}{l}\text { Number of participations in regular meetings, } \\
\text { mean }\end{array}$ & $1.32 \pm 0.65$ & $1.28 \pm 0.64$ & $1.23 \pm 0.50$ & $1.37 \pm 0.69$ & .004 \\
\hline
\end{tabular}

CES-D10, Center for Epidemiological Studies Depression; ADL, activities of daily living; IADL, instrumental activities of daily living

Table 3. Comparison and differences in the Korean-Mini-Mental State Examination score according to group and years ( $n=1262)$ 


\begin{tabular}{|c|c|c|c|c|c|c|c|c|c|c|}
\hline \multirow[t]{2}{*}{ Group } & $\begin{array}{l}2006- \\
2008\end{array}$ & \multirow[t]{2}{*}{$\mathrm{t}(p)$} & \multirow{2}{*}{$\begin{array}{l}2008- \\
2010 \\
\text { Mean } \pm S D\end{array}$} & \multirow[t]{2}{*}{$\mathrm{t}(p)$} & \multirow{2}{*}{$\begin{array}{l}2010- \\
2012 \\
\text { Mean } \pm S D\end{array}$} & \multirow[t]{2}{*}{$\mathrm{t}(p)$} & \multirow{2}{*}{$\begin{array}{l}2012- \\
2014 \\
\text { Mean } \pm S D\end{array}$} & \multirow[t]{2}{*}{$\mathrm{t}(p)$} & $\begin{array}{l}2014- \\
2016\end{array}$ & \multirow[t]{2}{*}{$t(p)$} \\
\hline & Mean $\pm S D$ & & & & & & & & Mean $\pm S D$ & \\
\hline $\begin{array}{l}\text { Moderate } \\
\text { and } \\
\text { severe } \\
\text { dementia } \\
(n=243)\end{array}$ & $-3.65 \pm 4.60$ & $-12.05(<.001)$ & $-0.49 \pm 5.18$ & $-1.52(.131)$ & $-1.41 \pm 5.15$ & $-3.91(<.001)$ & $-2.77 \pm 6.88$ & $-5.80(<.001)$ & $-3.60 \pm 6.31$ & $-8.53(<.001$ \\
\hline $\begin{array}{l}\text { Mild } \\
\text { dementia } \\
(n=267)\end{array}$ & $-2.03 \pm 3.98$ & $-8.07(<.001)$ & $-0.33 \pm 4.15$ & $-1.09(.275)$ & $-0.21 \pm 3.59$ & $-.55(.581)$ & $-1.14 \pm 4.82$ & $-3.76(<.001)$ & $-1.39 \pm 4.06$ & $-5.47(<.001$ \\
\hline $\begin{array}{l}\text { Normal } \\
(n=752)\end{array}$ & $-0.71 \pm 2.93$ & $-6.48(<.001)$ & $-0.37 \pm 3.50$ & $-2.65(.008)$ & $0.44 \pm 3.44$ & $3.23(.001)$ & $-0.32 \pm 3.16$ & $-2.89(.004)$ & $0.73 \pm 3.05$ & 6.54(<.001) \\
\hline
\end{tabular}

SD, standard deviation

Table 4. Risk factors for cognitive functional decline $(n=1262)$ 


\begin{tabular}{|c|c|c|}
\hline \multirow[t]{2}{*}{ Variables } & \multirow[b]{2}{*}{ B } & \multirow[b]{2}{*}{$p$-value } \\
\hline & & \\
\hline Age (y) & -0.044 & .001 \\
\hline Male (ref: female) & 0.591 & $<.001$ \\
\hline \multicolumn{3}{|l|}{ Education level (ref: College or higher) } \\
\hline Illiteracy & -1.954 & $<.001$ \\
\hline Elementary school graduate & -0.967 & $<.001$ \\
\hline Middle school graduate & -0.981 & .002 \\
\hline High school graduate & -0.582 & .005 \\
\hline Religion (ref: No) & 0.368 & $<.001$ \\
\hline Total household income (10,000 won) & 3.326 & .117 \\
\hline Regular exercise (ref: No) & 0.326 & $<.001$ \\
\hline No Depression (CES-D10) (ref: Yes) & 0.486 & $<.001$ \\
\hline Existence of spouse (ref: Yes) & -0.182 & .113 \\
\hline ADL score & -0.057 & $<.001$ \\
\hline IADL score & -0.239 & $<.001$ \\
\hline \multicolumn{3}{|l|}{ Number of meetings with friends (ref: Almost daily) } \\
\hline Less than 6 times a year & -0.550 & $<.001$ \\
\hline 1-4 times a month & 0.109 & 0.205 \\
\hline Number of participations in regular meetings & 0.009 & .899 \\
\hline Group 1: moderate and severe dementia (ref: Normal) & -0.503 & .034 \\
\hline Group 2: Mild dementia (ref: Normal) & -0.444 & .050 \\
\hline Time (y): 2008 (ref :2006) & -0.158 & $<.001$ \\
\hline Time (y): 2010 (ref :2006) & -0.922 & $<.001$ \\
\hline Time (y): 2012 (ref :2006) & -0.951 & $<.001$ \\
\hline Time (y): 2014 (ref :2006) & -1.214 & $<.001$ \\
\hline Time (y): 2016 (ref :2006) & -0.865 & $<.001$ \\
\hline Group 1 (Moderate and severe dementia)*time 2008 (ref: Normal *time 2006) & -2.922 & $<.001$ \\
\hline Group 1 (Moderate and severe dementia)*time 2010 (ref: Normal *time 2006) & -2.896 & $<.001$ \\
\hline Group 1 (Moderate and severe dementia)*time 2012 (ref: Normal *time 2006) & -4.536 & $<.001$ \\
\hline Group 1 (Moderate and severe dementia)*time 2014 (ref :Normal *time 2006) & -6.637 & $<.001$ \\
\hline Group 1 (Moderate and severe dementia)*time 2016 (ref: Normal *time 2006) & -10.422 & $<.001$ \\
\hline Group 2 (Mild dementia)*time 2008 (ref: Normal *time 2006) & -1.292 & $<.001$ \\
\hline Group 2 (Mild dementia)*time 2010 (ref: Normal *time 2006) & -1.225 & $<.001$ \\
\hline Group 2 (Mild dementia)*time 2012 (ref: Normal *time 2006) & -1.826 & $<.001$ \\
\hline Group 2 (Mild dementia)*time 2014 (ref: Normal *time 2006) & -2.699 & $<.001$ \\
\hline Group 2 (Mild dementia)*time 2016 (ref: Normal *time 2006) & -4.637 & $<.001$ \\
\hline
\end{tabular}

CES-D10, Center for Epidemiological Studies Depression; ADL, activities of daily living; IADL, instrumental activities of daily living

\section{Figures}




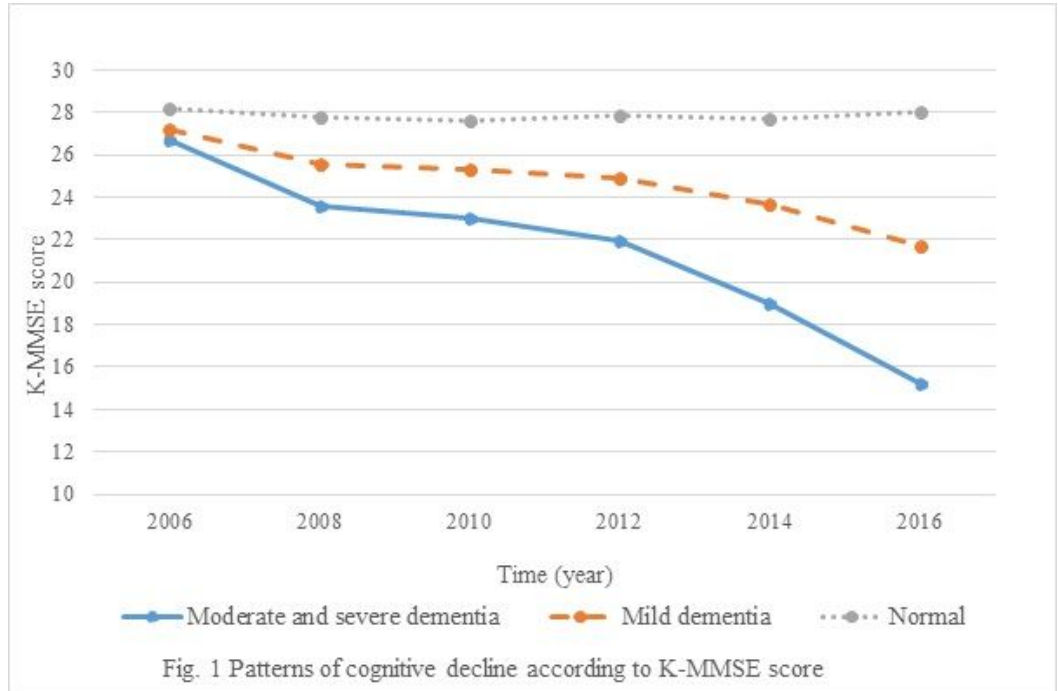

Figure 1

Patterns of cognitive decline according to K-MMSE score 